\title{
The Pedagogy of Error Correction: Surviving the Written Corrective Feedback Challenge
}

\author{
Danielle Guénette
}

Should we correct our students' language errors? Most ESL teachers would answer this question with a resounding Yes while at the same time wondering how to meet the challenge. The collaborative project reported below was designed to provide ESL teacher trainees with an opportunity to experience the ups and downs of providing corrective feedback on writing and develop their awareness in this regard. To this end, the teacher trainees acted as corrective-feedback tutors to high school learners during one school semester. During the course of the project, they kept journals documenting their reflections in regard to this demanding pedagogical practice. Time constraints, motivation, and fear of making mistakes themselves or of not providing adequate guidance to the learners were among the major hurdles encountered by the tutors. In interviews conducted at the end of the project, the tutors offered suggestions for overcoming these difficulties and surviving the corrective-feedback trials and tribulations. The survival tips presented were drawn from the tutors' recommendations as well as from insights from corrective-feedback research.

Devrait-on corriger les erreurs de langue de nos étudiants? La plupart des enseignants d'ALS répondraient à cette question par un oui catégorique tout en se demandant comment relever ce défi. Le projet collaboratif décrit ci-dessous a été conçu pour fournir aux stagiaires en ALS une occasion de vivre les hauts et les bas liés au fait de présenter de la rétroaction corrective aux travaux écrits, et de se conscientiser à cet égard. À cette fin, les stagiaires ont joué le rôle de tuteurs fournissant de la rétroaction corrective à des élèves du secondaire pendant un semestre. Au cours de projet, ils ont tenu un journal pour noter leurs réflexions relatives à cette pratique pédagogique exigeante. Parmi les obstacles les plus importants auxquels les tuteurs ont fait face, notons les contraintes de temps, la motivation et la peur de se tromper eux-mêmes ou de ne pas fournir des conseils adéquats aux élèves. Lors d'entrevues qui ont eu lieu à la fin du projet, les tuteurs ont offert des suggestions pour surmonter ces difficultés et survivre aux vicissitudes de la rétroaction corrective. Les conseils de survie présentés sont tirés des recommandations des tuteurs et des perspectives découlant de la recherche sur la rétroaction corrective.

A morning in the life of an ESL teacher ...

October 12, 8:45 a.m.: I hand back the essays my students wrote as practice for the upcoming exam. 
October 12, 9:05 a.m.: Two thirds of the essays that I spent the whole weekend commenting, praising, and correcting end up in the recycling bin.

Over the last 30 years, the topic of corrective feedback (CF) has generated a passionate debate fueled by the conflicting results of experimental studies that have investigated the effectiveness of various strategies to improve learners' accuracy in their second language (see Guénette, 2007, for a review). Some have suggested that indirect corrections (encouraging learners to selfcorrect by highlighting the errors, identifying the category of error with a code, or giving an explanation without providing the correct form) are preferable as they involve learners in cognitive problem-solving, whereas others have proposed that direct corrections (providing the correct form) might be equally effective, especially with low-proficiency learners or with specific categories of errors (Aljaafreh \& Lantolf, 1994; Bitchener, Young, \& Cameron, 2005; Chandler, 2003). However, despite this controversy, guidelines provided in English-as-a-second-language (ESL) and English-as-a-foreign language (EFL) programs in various countries prescribe the use of CF strategies that lead learners to focus on form through indirect corrections. Studies of teachers' feedback practices, however, indicate that direct correction is by far the preferred correction strategy of ESL and EFL teachers (Ferris, 2006; Furneaux, Paran, \& Fairfax, 2007; Lee, 2008). For L2 teachers who are looking for support for their pedagogical CF practices, this controversy only clouds the issue. After having met hundreds of ESL high school teachers in my capacity as a supervisor of teachers in training, I have come to realize that the frustration I felt on that morning of October 12 is shared by many of my colleagues, novice teachers as well as more experienced practitioners. These feelings of dissatisfaction led me to devise a project to prepare ESL teacher trainees for the challenges that lay ahead by providing them with an opportunity to experience the highs and lows of giving CF and to develop their practices in that regard. To this end, the teacher trainees interacted with high school students to whom they provided CF on learners' grammatical and lexical errors in texts written in their second language, English, for the duration of a school semester. See Guénette and Lyster (in press) for more information on the design and methodology of this study. Throughout the project, the teacher trainees also kept a journal documenting their reflections and questions about CF and one month after the project had ended, individual semistructured interviews were conducted to elaborate on some of the issues addressed in the journals and to discuss the challenges associated with the provision of $\mathrm{CF}$, as well as survival tips to overcome these challenges. Before presenting these tips, however, I describe the collaboration project and the context in which it took place; I then discuss the recurrent factors (see Appendix A) that were singled out by most of the teacher trainees as the major hurdles that they encountered. 


\section{The Project}

The teacher trainees $(n=18)$ were enrolled in their fifth semester of a fouryear TESL program. They had already completed several teaching methodology courses and a two-week internship in a secondary school classroom during their second term. The topic of $\mathrm{CF}$, although briefly addressed in some courses, is not dealt with systematically in the teacher training program. The high school learners $(n=64)$ were in secondary 3 (grade 9 in the English system) and had already received approximately 400 hours of English instruction focusing mostly on the development of oral skills. The tutors (the teacher trainees) were familiar with the linguistic content and specific objectives of the program, as well as the government-approved materials for ESL learners at that level. Each tutor was paired with two or three learners with whom they corresponded by e-mail for the entire semester.

As the focus to this point had been on the development of oral skills, it was decided with the agreement of the ESL teachers that the role of the tutor would be to provide CF to help the ESL learners improve their accuracy in writing (i.e., vocabulary, grammar, and mechanics) in accordance with the goals of the program. The tutors were encouraged to adapt their interventions to suit the needs of the learners, but they were free to select the CF strategy that they believed to be most appropriate. They could provide direct and indirect corrections, and they could correct selectively (focusing on certain categories of errors) or comprehensively (correcting all errors), and they were encouraged also to comment on content.

The project started with the tutors writing a personal message to the learners, introducing themselves and explaining the objective of the project. After this initial contact, the learners went to the school computer lab once every two weeks to write a text in English. The teacher suggested a writing topic, but some learners chose to write on another topic or simply to continue the "conversation" with the tutor sparked in earlier messages. They then emailed this text to their tutors, who returned their corrections and comments electronically. On receiving the corrected texts, the teacher encouraged the learners to review the corrections and to try to incorporate their tutors' suggestions into their new pieces of writing. The learners wrote between four and six texts that were corrected by the tutors during the semester.

\section{Hurdles Identified by the Tutors}

The tutors in this program identified a number of challenges.

\section{Adapting and Catering to Individual Needs}

One of the greatest concerns for the tutors was adapting their feedback to varied proficiency levels. In general, the tutors reported having more difficulty with weaker students because they often had to read the text several 
times in order to understand it. Then they had to choose not only which errors to focus on and which corrective strategy to use, but also had to decide how to address complex linguistic features with simple explanations that the learners would understand. In addition, tutors who were determined to personalize their CF found it difficult to isolate exactly which linguistic feature to focus on in order to help the learner improve. Another issue was the tutors' concern that if they did not correct all the mistakes, the learners might think that what they had written was accurate, and they would retain these forms permanently. Some tutors feared that more advanced students, who were aware that they had made a mistake without necessarily knowing how to fix it, would judge them as incompetent or lazy if they had not flagged the error.

\section{Diagnosing Errors}

Correctly diagnosing the categories of error presented a challenge for some tutors, who reported spending considerable time and energy reading their grammar books. Tutors were also afraid of making mistakes themselves, of not understanding what the student meant, or of not providing accurate grammatical explanations. As Myhill (2000) noted, most second-language teachers are neither grammarians nor linguists, and their metalinguistic knowledge is sometimes partial or tentative. For example, the learners made many errors with the base form of verbs: either they omitted the to, as in "I love swim," which mirrors the French structure "J'aime nager," or they replaced the to with for, as infinitives in French can be preceded by the preposition pour, which in most cases accurately translates as for. The tutors did not always know how to categorize these errors: they flagged them variously as errors in prepositions, lexis, or verb forms.

\section{Fear of Discouraging the Learners}

Several tutors feared the effects of the "red pen" on their learners' motivation; they also worried about hurting the learners' feelings and damaging their self-esteem. As a result, they opted for selective corrections, but did not always know which errors should have been the focus of attention. A few tutors candidly admitted flagging errors that "annoyed" them, such as spelling mistakes or punctuation. Others focused on repetitive errors or errors that hindered communication, which, intuitively seemed to be exactly the right course of action. But they also feared, as mentioned above, that errors ignored would become permanent features of the learners' language repertoire.

\section{Maintaining Motivation}

The issue of time and lack of improvement in the learners' writing over the semester were mentioned by several tutors as factors that reduced their motivation to provide feedback. Although the tutors had interacted with only three or four students, the time needed to reflect on the learners' proficiency 
level and capacity to self-correct became a major deterrent to personalizing their feedback. This also led them to assume that in the future, individualizing their feedback would not be a practice that they could realistically adopt, as a typical teaching load at the high school level is six groups of 30 students. The tutors who were paired, strictly by chance, with both low-proficiency and more advanced learners could not help but compare and question why some learners did not seem to respond to feedback. Some reported that not seeing much improvement in the learners, nor evidence of interest in improving their writing, had a significant effect on their own motivation to spend more time and effort providing feedback.

This experience of providing CF to learners over a period heightened the tutors' awareness of the complexity of this pedagogical task and led them to reflect on the practices that they would like to adopt in the future to turn the $\mathrm{CF}$ challenge into a positive teaching and learning experience for both themselves and the learners. The survival tips presented below emerged from conversations with the tutors and I hope will prove useful to all teachers who are about to embark on-or are already engaged in - the corrective feedback adventure.

\section{Survival Tips}

Survival tip \#1: Do not adopt a one-size-fits-all behavior

There are many ways to have learners correct their errors (peer feedback, conferences, electronic feedback, etc.), but I restrict this to a discussion of traditional CF methods, that is, direct or indirect corrections. For the teacher, providing corrective feedback is essentially a choice between acting as the provider (providing the correct form) or the initiator (providing help through various techniques but withholding the correct form). These roles were identified by Furneaux et al. (2007). However, catering to students' individual needs also implies that over and above choosing the appropriate corrective feedback strategy, teachers should consider the type of error committed by the learner. As revealed in the research on $\mathrm{CF}$, some categories of errors have been shown to be better candidates for direct correction (e.g., word choice), whereas others (e.g., rule-governed items such as subject-verb agreement) can be more effectively treated with indirect correction (Bitchener \& Ferris, 2011). Direct corrections do not lead the learners to think about the language, but they may help those who are not yet proficient enough to self-correct as they model what is acceptable in the second language. Indirect corrections, on the other hand, push the learners to question their hypotheses about the language, but they may also lead to frustration. Yet as the tutors discovered through their experience, both strategies can and should be used. For linguistic notions that the learners have been exposed to or are expected to know, it makes sense to provide indirect corrections with or without brief 
explanations or simply reminders to consult their notes or other resources. In contrast, for features that are clearly outside the realm of the learners or that have not been the subject of instruction, direct corrections can be used, or errors can simply be ignored. Direct corrections can also be the strategy of choice when teachers are unsure of the underlying cause of the error or of the appropriate metalinguistic explanation. In such cases, it is easier, less time-consuming, and more productive for the teacher to provide the correct form or simply to underline the error, rather than to mislabel it with an inaccurate code or to misinterpret what the student had in mind.

\section{Survival tip \#2: Be selective about what you correct}

Teachers can overcome their fear of discouraging learners by providing focused feedback. "How would you feel if your boss only pointed out every little thing you did wrong?" asked one tutor to explain why, although she had provided comprehensive correction, she would not adopt that practice in the future. But as she also noted, correcting selectively is only efficacious for the learner if the focus of the CF is individualized or related to the instructional objectives. This is especially true with learners who are not yet proficient in their second language, in which case it is acceptable simply to ignore some errors. Teachers should adapt their correction focus to the context-type of text, genre, audience, purpose-and notify the learners what to expect. Teachers might simply flag the errors in the first and last paragraphs of an essay and have students self-correct the rest of the text. Instead of correcting individual papers, they can target common errors and provide mini-lessons to the group. They can also design short writing tasks that have the learners use certain linguistic features and limit their feedback to those features. Then as learners progress in their mastery of the language, teachers can gradually individualize their feedback or increase the number of linguistic features on which they focus. Teachers who are working in a communicative framework and who often ignore their learners' spoken errors if there is communication breakdown could also extend that tolerance to their learners' written errors, remembering that writing should not be concerned with accuracy only, but should also "stimulate the use of new language" (Bruton, 2009, p. 607).

\section{Survival tip \#3: Do not correct everything the learners write}

Just as most teachers do not provide CF systematically every time their students express themselves orally in the second language, it is not mandatory to correct or comment on every text that students write. A recent meta-analysis of the effectiveness of writing practices in literacy instruction (L1) provided evidence that writing can improve reading (Graham \& Hebert, 2010). It would appear reasonable to predict that the reverse may also be true, and that reading can improve writing. If we push this logic further, it would also 
make sense to assume that writing can improve writing, in both the first and second language, even without intervention from the teacher. Learners should be encouraged to engage in writing activities that do not necessarily end up in the teacher's in-basket for correction purposes, thus freeing the teacher's time for more productive classroom activities. As suggested by Bruton (2009), "a little, a lot," is better than "a lot, a little" (p. 608); in other words, writing short texts frequently and regularly is better in the long run than writing longer texts less often. Learners can also keep a journal where they note their reflections on their learning and their opinions or personal responses to what they read or hear in class; these personal notes do not need to be corrected for form.

\section{Survival tip \#4: Train learners to self-edit}

One tutor's conclusion at the end of the project was that CF needed a followup. "Ideally I would ask them to rewrite their text according to my corrections ... I think the main thing is, I would really need to see feedback coming from them." If learners are not asked to revise or rewrite, the teacher cannot be sure that they noticed the correction; if they have not, as Chandler (2009) maintains, it is equivalent to not having been corrected at all: and it also means that teachers may have wasted their time. For learners to truly benefit from $\mathrm{CF}$, they must be held accountable for revising or rewriting their texts. Yet the process of revision is far from simple, and noticing an error is not the same as being able to correct it. Self-editing is a skill that like any other must be taught and practiced (Ferris, 1995; Simard, 1995). As one tutor suggested, one way to make the rewriting task less mechanical and to ensure that the students pay attention to the corrections is to provide direct corrections for the first two tokens of a specific category of error and underline all the other instances of the same category in another color. Students can then recopy and revise using the model provided by the teacher. Some tutors in this project used correction keys, but as one of them remarked, learners should also take an active part in their learning process by creating their own correction key based on the errors flagged by the teacher on their written texts. This correction key can then serve as a self-editing checklist for subsequent pieces of writing. It can also help teachers customize their feedback as they can select the features to correct from the checklist provided by the students or ask the learners themselves to select the linguistic features on which they would like to receive feedback. Teachers should ensure that texts that they have marked and that were recopied or revised by the learners do not go in the recycling bin at the end of class. These pieces of writing should be used as mementos of what the students need to work on and should be inserted in a writing binder, a portfolio, or a writing booklet. By sharing responsibility for correction with the learners, teachers will feel that their time has been well invested, and this in turn will enhance motivation to continue with the correction crusade. 


\section{Survival tip \#5: Put things into perspective}

Tutors mentioned how frustrated they felt at seeing the same errors repeated time and time again in their learners' texts; it reminded them that learning and becoming fluent in a second language is a process that takes time. Before sitting down to mark 120 compositions on the topic of "My Last Holiday," teachers should remember that if students were already accurate in their second language, they would probably not need their feedback. With the realization that perfection is not of this world comes acceptance that mistakes are not only acceptable (Ferris \& Hedgcock, 1998), but are helpful as they provide teachers with information for planning future instruction and remedial activities. As with any other skill, accuracy in writing will develop through time, exposure, and abundant opportunities to practice, although we cannot expect second-language learners to have the intuition of first-language writers. We should also remember that knowledge learned through explicit teaching may not become integrated to the extent that learners can access it without effort (Ellis, 2002). Teachers should provide appropriate feedback at the right time, in the right way, and in the proper context (Guénette, 2007). However, irrespective of the time and effort that teachers put into providing feedback, learners will continue to make errors, and some will progress more slowly than others. Rather than becoming frustrated, teachers should rejoice when they notice progress, however small, and see their efforts and those of their students rewarded.

\section{Conclusion}

From both pedagogical and ecological perspectives, teachers see it as their professional responsibility to provide CF to their learners, and students expect it and generally feel that it is beneficial (Hyland \& Hyland, 2001). In a highly communicative classroom, the provision of corrective feedback may be the most important activity on which teachers explicitly focus on form (Frodesen \& Holten, 2003). But feedback on writing also serves other purposes. It is the interactional strategy par excellence, a privileged moment in which each learner can benefit from the teacher's full attention. Thus ultimately, the dilemma for teachers is not "to correct or not to correct" (Calvé, 1992) or even "how, when, and what to correct," but rather, as one tutor expressed it, finding the most helpful, realistic, and productive way to "show students that you care" through the feedback that you provide.

\section{The Author}

After teaching ESL in high school for several years, Danielle Guénette obtained her doctorate from McGill University and is now an associate professor in the Second Languages program at Université du Québec à Montréal. Her research interests are corrective feedback on writing and L2 teacher training and professional development. 


\section{References}

Aljaafreh, A., \& Lantolf, J.P. (1994). Negative feedback as regulation and second language learning in the zone of proximal development. Modern Language Journal, 78, 465-483.

Bitchener, J., \& Ferris, D.R. (2011). Written corrective feedback in second language acquisition and writing. New York: Routledge.

Bitchener, J., Young, S., \& Cameron, D. (2005). The effect of different types of corrective feedback on ESL student writing. Journal of Second Language Writing, 14, 191-205.

Bruton, A. (2009). Improving accuracy is not the only reason for writing, and even if it were ... System, 37, 600-613.

Calvé, P. (1992). Corriger ou ne pas corriger, là n'est pas la question. Canadian Modern Language Review, 48, 458-471.

Chandler, J. (2003). The efficacy of various kinds of error feedback for improvement in the accuracy and fluency of L2 student writing. Journal of Second Language Writing, 12, 267-296.

Chandler, J. (2009). Response to Truscott. Journal of Second Language Writing, 18, 57-58.

Ellis, R. (2002). The place of grammar instruction in the second/foreign language curriculum. In E. Hinkel \& S. Fotos (Eds.), New perspectives on grammar teaching in second language classrooms (pp. 17-35). Mahwah, NJ: Erlbaum.

Ferris, D. (1995). Teaching students to self-edit. TESOL Journal, 4, 18-22.

Ferris, D. (2006). Does error feedback help student writers? New evidence on the short- and long-term effects of written error correction. In K. Hyland \& F. Hyland (Eds.), Feedback in second language writing: Contexts and issues (pp. 81-104). Cambridge, UK: Cambridge University Press.

Ferris, D.R., \& Hedgcock, J.S. (1998). Teaching ESL composition: Purpose, process, and practice. Mahwah, NJ: Erlbaum.

Frodesen, J., \& Holten, C. (2003). Grammar and the ESL writing class. In B. Kroll (Ed.), Exploring the dynamics of second language writing (pp. 141-161). Cambridge, UK: Cambridge University Press.

Furneaux, C., Paran, A., \& Fairfax, B. (2007). Teacher stance as reflected in feedback on student writing: An empirical study of secondary school teachers in five countries. International Review of Applied Linguistics in Language Teaching, 45, 69-94.

Graham, S., \& Hebert, M. (2010). Writing to read: Evidence for how writing can improve reading. A report from Carnegie Corporation of New York. Washington, DC: Alliance for Excellent Education.

Guénette, D. (2007). Is feedback pedagogically correct? Research design issues in studies of feedback on writing. Journal of Second Language Writing, 16, 40-53.

Guénette, D., \& Lyster, R. (in press). The written corrective feedback practices of pre-service ESL teachers. Canadian Modern Language Review, 69(1).

Hyland, F., \& Hyland, K. (2001). Sugaring the pill: Praise and criticism in written feedback. Journal of Second Language Writing, 10, 185-212.

Lee, I. (2008). Understanding teachers' written feedback practices in Hong Kong secondary classrooms. Journal of Second Language Writing, 17, 69-85.

Myhill, D. (2000). Misconceptions and difficulties in the acquisition of metalinguistic knowledge. Language and Education, 14(3), 151-163.

Simard, C. (1995). L'orthographe d'usage chez les étudiants des ordres postsecondaires. Revue des sciences de l'éducation, 21(1), 145-165. 


\section{Appendix A}

Themes and Related Topics Addressed in the Interviews

\begin{tabular}{ll}
\hline Challenges & Links between feedback and instruction \\
& Perceived proficiency levels \\
& Providing models \\
& Providing suggestions when unsure of meaning \\
& Perceived proficiency levels \\
& Time constraints \\
& Types of errors difficult to correct \\
& Fear of making mistakes \\
& Remaining neutral and objective \\
& Motivation \\
& Feelings of frustration
\end{tabular}

